\title{
A Teoria do Conhecimento e sua relação com a Metafísica nas Lições de Husserl em Göttingen
}

\author{
The Theory of Knowledge and its relationship with \\ Metaphysics in Husserl's Lessons in Göttingen \\ Carlos Diógenes Cortes Tourinho*
}

\begin{abstract}
Resumo: O presente artigo se concentra nas lições apresentadas por Husserl em Göttingen, de 1902 a 1909. Tem como objetivo mostrar que a elucidação da dupla tarefa da teoria do conhecimento é o que permite compreender o deslocamento do problema acerca da possibilidade do conhecimento para a aspiração por uma "eidética do conhecimento", esclarecendo como a referida teoria se converteria em uma "fenomenologia do conhecimento". O artigo pretende mostrar ainda que, no exercício de tais tarefas, especialmente, da apreensão intuitiva do ser do fenômeno cognoscitivo, a teoria do conhecimento enquanto fenomenologia do conhecimento - revelaria uma "vocação" para a fundamentação da metafísica.
\end{abstract}

Palavras chave: Edmund Husserl. teoria do conhecimento. tarefa crítica. fenomenologia do conhecimento. metafísica.

\begin{abstract}
The present paper focuses on the lessons presented by Husserl in Göttingen from 1902 to 1909. Its objective is to show that the elucidation of the dual task of the theory of knowledge is what allows to understand the displacement of the problem about the possibility of knowledge for the aspiration by an "eidetics of knowledge", clarifying how the theory of knowledge would convert in a "phenomenology of knowledge". The paper also intends to show that in the exercise of such tasks, especially of the intuitive apprehension of the being of the cognitive phenomenon, the knowledge theory - as phenomenology of knowledge - would reveal

Key words: Edmund Husserl. theory of knowledge. Critical Task. Phenomenology of Knowledge. Metaphysics.
\end{abstract}

\section{Introdução}

de Göttingen, uma apresentação Um olhar panorâmico sobre o iti- elucidativa das tarefas exercidas nerário traçado por Edmund Hus- pela teoria do conhecimento, asserl permite-nos notar, no período sim como destacar o papel prepon-

${ }^{*}$ Professor adjunto da Universidade Federal Fluminense (UFF). 
derante de tais tarefas na clarifi- ao estatuto de "fenomenologia do cação do projeto da fenomenolo- conhecimento"; 3) por fim, mostrar gia já na primeira década do séc. que, no cumprimento de sua tarefa XX. Husserl chama-nos à atenção crítica, a teoria do conhecimento para o exercício de uma dupla ta- revelaria, de acordo com Husserl, refa da teoria do conhecimento: uma "vocação" para a fundamenuma crítica e outra positiva. A tação da metafísica. O estudo das primeira delas consistiria em de- referidas lições se torna, particununciar as formas de ceticismo - e larmente, importante no itineráseus respectivos contrassensos teo- rio husserliano, na medida em que réticos - em relação à possibilidade atesta o esforço de Husserl em eludo conhecimento, ao passo que cidar a nova posição assumida pela a segunda aspiraria a uma apre- fenomenologia, bem como as priensão da essência do fenômeno meiras palavras do autor sobre a cognoscitivo. No presente artigo, especificidade do método da recom base nas lições proferidas por dução fenomenológica, passo deHusserl em Göttingen, especifica- cisivo para a consolidação da femente, de 1902 a 1909, pretende- nomenologia como um novo idese: 1) apresentar e elucidar a es- alismo transcendental no século pecificidade de tais tarefas; 2) evi- $\mathrm{XX}^{2}$.

denciar, na passagem da primeira para a segunda tarefa, o deslocamento do problema epistêmico acerca da possibilidade do conhecimento para a aspiração husserliana por uma eidética do conhecimento, permitindo-nos compreender como a teoria do conhecimento seria, para Husserl, alçada

Para cumprir tais objetivos, o presente artigo irá se concentrar em um elenco de lições proferidas por Husserl no período de Göttingen, de 1902 a 1909. Mais particularmente, será dedicada uma atenção especial ao Capítulo 5 das lições de 1906/1907, bem como às "Cinco Lições" ("Fünf Vorle-

\footnotetext{
${ }^{2}$ Mohanty afirma-nos que, especificamente, os anos de 1905-1910 seriam os anos durante os quais Husserl faria as descobertas mais importantes de sua vida, descobertas que determinariam os rumos do seu pensamento. Cf. Mohanty, J. N. "The development of Husserl's thought”, p. 57. Housset afirma-nos, a respeito da virada idealista de 1907, que: “... sem ser a mais notória, é todavia a mais decisiva.... a fenomenologia de Husserl nela toma consciência do seu próprio princípio e este fato contém em potência todos os alargamentos futuros”. Cf. Housset, E. Husserl et l'enigme du monde, p. 60.
} 
sungen") de abril-maio de 1907, publicadas, respectivamente, sob os títulos de Introdução à Lógica e Teoria do Conhecimento (Einleitung in die Logik und Erkenntnistheorie) e A Ideia da Fenomenologia (Die Idee der Phänomenologie). Mas, o artigo também recorrerá a passagens das lições de 1902/1903, assim como das lições de 1909, intituladas, nessa ordem, "Teoria Geral do Conhecimento" (Allgemeine Erkenntnistheorie) e "Introdução à Fenomenologia do Conhecimento" (Einführung in die Phänomenologie der Erkenntnis). Examinemos, então, mais pormenorizadamente, cada uma das tarefas exercidas pela teoria do conhecimento nas referidas lições de Husserl, de modo que possamos perceber o deslocamento do problema teórico-cognoscitivo acerca da possibilidade do conhecimento para a tal aspiração husserliana por uma eidética do conhecimento, examinando, por fim, a relação entre teoria do conhecimento e metafísica no contexto das referidas lições do período de Göttingen.

\section{A tarefa crítica: denunciar o contrassenso teóricoinerente às formas de ceticismo}

No período de Göttingen, Husserl afirma-nos que o modo de consideração natural perante o mundo adotado habitualmente pelos homens, bem como pelas ciências positivas da natureza, considera o conhecimento como uma obviedade. Pode-se dizer que tal modo de consideração encontra-se apoiado na doutrina do naturalismo, para a qual pensar o mundo consiste em pensá-lo como uma realidade de fatos naturais, na qual o homem (como ente psicofísico e, portanto, como um "fato natural" em meio a outros fatos) estaria confinado a uma relação meramente empírica com os demais entes que habitam o seu mundo circundante. Ao adotar tal atitude, caberia ao homem de ciência, em uma vivência supostamente cognoscitiva, observar sistematicamente o fenômeno positivo, descrever a sua regularidade, para inferir, enfim, uma generalização empírica. Conforme Husserl esclarece, mergulhada no pensamento natural, a ciência dita "positiva" mostra-se despreocupada quanto às dificuldades da possibilidade do conhecimento, pois, a mesma considera como óbvia tal possibilidade. Pode-se dizer, com isso, que a referida ciência mani- 
festa, do ponto de vista filosófico, uma ingenuidade no realismo que adota frente ao objeto que investiga, uma vez que a mesma não se interroga pelo sentido da objetividade que ela própria considera como dada, ou como inquestionável. No § 32 do Capítulo 5 das lições de 1906/1907, publicadas sob o título de Introdução à Lógica e Teoria do Conhecimento, Husserl lembra-nos que tais ciências positivas se encontram em um "paraíso de inocência teóricocognoscitiva" (Paradies der erkenntnistheoretischen Unschuld). As ciências progridem de maneira inabalável até que seja exercida uma "reflexão teórico-cognoscitiva" (erkenntnistheoretische Reflexion) sobre o sentido ou a validade da objetividade do mundo que tais ciências consideram como óbvia. Husserl chega mesmo a dizer, nos $\S \S$ 32 e 33 do Capítulo 5 das referidas lições, que ousar exercer esta reflexão consistiria em algo como comer a "maçã proibida" (verbotene Apfel) da "árvore do conhecimento filosófico" (philosophischen Erkenntnis Baum), o que implicaria numa espécie de expulsão deste paraíso de inocência teóricocognoscitiva. Deste modo, em sua inocência epistemológica, a ciência positiva "dá às costas" para a questão colocada pela teoria do conhecimento: afinal, em que se fundamenta a suposta relação de correspondência entre a vivência dita cognoscitiva e as coisas que lhe são transcendentes? O que o pensamento natural considera como óbvio e livre de questionamentos, a reflexão teórico-cognoscitiva exercida sobre a relação da vivência cognoscitiva com o que lhe é transcendente - revela-nos como um enigma, designado por Husserl de "enigma do conhecimento natural" (Rätsel der natürlichen Erkenntnis). Tal reflexão coloca-nos, assim, frente a frente, com a questão ignorada pelo pensamento natural adotado pelas ciências positivas.

Abrem-se as portas para o exercício da "tarefa crítica" (kritische Aufgabe) da teoria do conhecimento, cujo propósito será o de denunciar o contrassenso a que nos conduz certas formas de ceticismo em relação à temática do conhecimento. Como o próprio Husserl nos diz, nas lições de 1906/1907, no Apêndice A, VIII, § 33: "Superar o ceticismo é a tarefa permanente da teoria do conhecimento" (HUSSERL, [1906/1907] 1984, p. 
367). O exercício da tarefa crítica blemas de fundamentos), o pensapermite-nos, inicialmente, identi- mento natural confina-nos a uma ficar que, ao ignorar o caráter enig- relação meramente empírica com mático do conhecimento transcen- as coisas, através da qual inferidente, a posição assumida pelas mos, como nos diz Husserl, desde ciências naturais implica em um 1900, em Prolegômenos à Lógica ceticismo obscuro (ou não decla- Pura (Prolegomena zur reinen Lorado), na medida em que o mesmo gik), "generalizações vagas da exse torna inapercebido por tais ci- periência" (vage Verallgemeinerunências. No $\S 33$ do referido Apên- gen der Erfahrung). Assim, em dice das lições de 1906/1907, Hus- tal atitude, por mais êxito que serl chamará este ceticismo não o pensamento obtenha em operar declarado de "inconsciente" (un- tais inferências a partir da obserbewussten Skeptizismus) ${ }^{3}$, chegando vação sistematizada de fatos, fica mesmo a compará-lo ao verme da confinado a proposições cuja validúvida ou obscuridade (der Wurm dade se torna meramente empírica des Zweifels oder der Unklarheit), e que, enquanto tais, não perdem escondido em todo conhecimento o seu cariz contingente, não nos lidado como "definitivo" (bestimm- vrando, por conseguinte, do asséten) e que vai, aos poucos, corro- dio da dúvida e do que não é inendo e destruindo a tomada de po- teiramente evidente. Afinal, como sição ingênua assumida pelas ci- nos diz Husserl, pouco tempo deências positivas quanto ao conhe- pois da publicação de Prolegômecimento. Ao conceber o mundo nos, nas lições de 1902/1903: "Nós como uma realidade de fatos natu- não extraímos necessidades e unirais, considerando inclusive o pró- versalidades da experiência, que prio pensamento como um fato na- o somatório de fatos individuais tural (colapsando a distinção ne- não pode nos dar" (HUSSERL, cessária entre o ato de pensar e o [1902/1903] 2001, p. 84). Há, conteúdo ideal do pensamento, o portanto, aos olhos de Husserl, em que, por si só, nos conduz a pro- tal modo de consideração natural,

\footnotetext{
${ }^{3}$ Husserl emprega este termo desde as lições de 1902/1903, afirmando-nos que: "Quase todas as teorias do conhecimento falsas contêm um ceticismo inconsciente..." "Fast jede falsche Erkenntnistheorie ist unbewusster Skeptizismus”).Cf. Husserl, E.Allgemeine Erkenntnistheorie - Vorlesung 1902/03, p. 87.
} 
um ceticismo iminente. Se afirmarmos, em conformidade com o pensamento natural, a tese segundo a qual "todas" as proposições inferidas pelo pensamento são generalizações da experiência e, por isso, na medida em que carecem de validade absoluta, são proposições passíveis de questionamento, estaremos supondo, ao menos, que a própria tese afirmada é uma exceção à regra. Do contrário, ela própria seria também o resultado de uma inferência da experiência, consistindo, portanto, em uma generalização empírica que, como tal, é contingente. Eis o que permanece desconhecido pelas ciências naturais e, ao mesmo tempo, denunciado pela tarefa crítica da teoria do conhecimento: o contrassenso a que nos conduz o ceticismo inerente ao pensamento natural adotado por tais ciências.

Se a reflexão exercida sobre o problema do conhecimento transcendente coloca-nos frente à questão levantada pela teoria do conhecimento, abrindo as portas para o exercício de sua tarefa crítica, livrando-nos da ingenuidade epistêmica do modo de consideração adotado pelas ciências positivas, não é certo, contudo, que tal re- flexão nos livre inteiramente da incidência do ceticismo em relação ao conhecimento: "Estamos em perigo permanente de deslizar para o ceticismo", nos diz Husserl nas "Cinco Lições", proferidas em abril-maio de 1907 (HUSSERL, [1907] 1950, p. 21). Husserl mostra-nos, porém, que se trata agora de um ceticismo "manifesto" (offenen Skeptizismus), para o qual a reflexão a respeito do conhecimento transcendente e, por conseguinte, a constatação de seu caráter enigmático, coloca-nos diante de um obstáculo em relação à possibilidade do conhecimento em geral: afinal, como é possível que uma vivência intencional, supostamente cognoscitiva, possa visar o que lhe é transcendente e, portanto, o que se encontra fora de si mesma? Ao considerar que toda vivência dita cognoscitiva se depare, inevitavelmente, com este problema, o ceticismo não hesitará em afirmar que o que vale para o conhecimento transcendente valerá para toda e qualquer forma de conhecimento. O ceticismo manifesto generaliza, assim, o caráter enigmático do conhecimento transcendente para o conhecimento em geral. Daí Husserl perguntar, no Apêndice $B$, das 
lições de 1906/1907:

Estaríamos nós mesmos confinados a duvidar da possibilidade do conhecimento, inteiramente inclinados ao ceticismo, inclinados à negação do conhecimento e decidir, com efeito, que não pode haver qualquer conhecimento? Estaríamos nós diante de uma medicina mentis que pudesse nos curar desta doença? (HUSSERL, [1906/1907] 1984, p. 397).

Mas, lembra-nos Husserl que, ao promover tal generalização, o referido ceticismo não deixa de supor a própria vivência de cogitar, livrando-a - sem se dar conta disso - do assédio da dúvida e do questionamento. Em meio à generalização do caráter enigmático do conhecimento transcendente, o ceticismo manifesto não percebe que supõe, com evidência indubitável, a própria vivência de generalização deste questionamento. Trata-se do que Husserl chamará de "evidência da cogitatio" (Evidenz der cogitatio), retomando - de maneira "convenientemente modificada", como ele gosta de dizer - as famosas passagens das Meditações de Descartes.
A constatação desta certeza indicanos o contrassenso do ceticismo manifesto: não poder generalizar o caráter enigmático do conhecimento transcendente sem que, ao considerar toda forma de conhecimento como "enigmático" (rätselhaft), se depare com a certeza da própria cogitatio em meio a esta generalização. Daí Husserl dizer, no § 34 do Capítulo V das lições de 1906/1907, a propósito desse contrassenso do ceticismo manifesto, que a tese segundo a qual "todo conhecimento é problemático" é uma tese ambígua, pois, não posso afirmá-la sem que abra uma exceção para ela própria e, com isso, contradiga-a. Em outros termos, nas lições anteriores de 1902/1903, o autor parece nos chamar a atenção para o mesmo tipo de consideração, afirmando-nos que: se a verdade é relativa a cada homem e, portanto, não há nenhuma verdade universal, encontramos aí, então, ao menos, um conteúdo de pensamento que parece transcender às individualidades (HUSSERL, [1902/1903] 2001). Tratase, portanto, de uma tese na qual notamos "no ceticismo, a razão em contradição consigo mesma..." (HUSSERL, [1902/1903] 2001, p. 
85). Daí Husserl considerar, nas mesmas lições de 1902/1903, este tipo de ceticismo como uma "teoria do conhecimento negativa" (negative Erkenntnistheorie) (HUSSERL, [1902/1903] 2001, p. 88). Nos termos do autor, alguns anos mais tarde: “...se conhecimento em geral torna-se um problema para nós, então, algum conhecimento já está implicado nisto, conhecimento absolutamente indubitável, a saber, que o conhecimento em geral é problemático..." (HUSSERL, [1906/1907] 1984, p. 193). Mas, a constatação desta certeza nos indica também que se o exercício reflexivo, bem como a constatação do caráter enigmático do conhecimento transcendente, abre-nos outro caminho que não aquele trilhado pelo ceticismo manifesto, é na medida em que se pode constatar, com a tarefa crítica da teoria do conhecimento, que se o conhecimento dito "transcendente" é enigmático, isto não nos autoria dizer que todo conhecimento o seja. O próprio Husserl nos diz, nas "Cinco Lições", que: "O conhecimento não se nega nem se declara em todo o sentido como algo de duvidoso pelo fato de se "por em questão'...” (HUSSERL, [1907]
1950, p. 4). A referida tarefa teria, portanto, dois momentos cruciais: o primeiro traz à baila o enigma do conhecimento transcendente, ao passo que o segundo impede a generalização de tal enigma para toda e qualquer forma de conhecimento. E é justamente para o domínio do conhecimento não assediado por este enigma que as atenções se voltarão. Abre-se, então, um novo domínio de investigação (fundamental para as pretensões da fenomenologia): o domínio do conhecimento dito "não enigmático".

Porém, Husserl adverte-nos para o caráter propriamente psicológico da evidência da cogitatio. Afinal de contas, trata-se da certeza da "minha cogitatio" (da vivência psicológica de um homem efetivo que afirma, nega, duvida, etc). Tal certeza é a de uma imanência psicológica e não se encontra, portanto, inteiramente depurada de toda transcendência (isto é, daquilo que insiste em não ser inteiramente evidente, conservando ainda o assédio da dúvida). Se a evidência da cogitatio é, num primeiro momento, uma resposta eficaz ao ceticismo manifesto, o seu caráter psicológico coloca a teoria 
do conhecimento diante de um desafio: adotar uma estratégia metodológica por intermédio da qual pudesse se abrir um campo, em cuja imanência tudo aquilo que aparecesse pudesse, então, se dar originariamente e, portanto, com evidenciação máxima, livre das limitações que a relação empírica com o mundo circundante insiste em nos impor ${ }^{4}$.

Tal estratégia consiste no exercício da epoché fenomenológica, por meio da qual renuncio a fazer considerações a respeito de tudo o que não me é revelado como um dado efetivo e absoluto. Atribuise, aqui, nos termos das "Cinco Lições", um "índice de nulidade" (Index der Nullität) ao que é transcendente e, portanto, a todo o domínio empírico-natural sobre o qual agem as ciências positivas. Mas, e quanto à evidência da cogitatio? Uma vez que se trata da certeza imediata da ocorrência da vivência de cogitar (de afirmar, de negar, de duvidar, etc.) que, como tal, é vivência psicológica e, portanto, própria de um eu empírico, tal certeza não é ainda a de um dado absoluto. Por este motivo, a própria evidência da cogitatio deverá, segundo Husserl, cair sob o tal índice de nulidade, considerado um passo decisivo para o exercício da redução fenomenológica. Aqui, cabe-nos esclarecer que a epoché fenomenológica é uma espécie de recurso por meio do qual a redução fenomenológica passa a ser exercida. Husserl chega mesmo a dizer, no $\S 34$ do Capítulo 5 das lições de 1906/1907, que a epoché seria apenas o "pedaço de um método" (Bestandstück einer Methode). Nos termos do autor: "A suspensão de juízo não é um método de obtenção de conhecimento; no máximo, é um pedaço do método. A suspensão de juízo apenas pode ser algo temporário e transitório, ou algo que não é de todo modo ilimitado..." (HUSSERL, [1906/1907] 1984, p. 195). Trata-se, portanto, de uma estratégia metodológica inicial por intermédio da qual exercemos o método propriamente dito da redução fenomenológica. Tal estratégia terá um caráter "expansivo", uma vez que amplia a suspenção do juízo em rela-

\footnotetext{
${ }^{4}$ Sobre o desafio metodológico que se impõe à fenomenologia de Husserl (Cf. Tourinho, C. D. C. "O desafio metodológico de Husserl, o exercício generalizado da epoché e o estatuto transcendental da objetividade fenomenológica". In: Revista Portuguesa de Filosofia - Fenomenologia e Filosofia Prática, V 71, No 1, 2015, pp. 11-25).
} 
ção à posição de existência das coisas, do eu empírico que a vivencia, bem como de suas vivências psicológicas. Reduz-se, por conseguinte, a própria imanência em sentido psicológico: “...imanência na consciência dos homens e no fenômeno psíquico real" (HUSSERL, [1907] 1950, p. 7). Tal ampliação da suspensão de juízo é motivada pela exigência de que a imanência - enquanto imanência psicológica e, portanto, considerada como "acontecimento real" (reales Vorkommnis) - fosse depurada de todo o resquício de transcendência (dúvidas e incertezas) que em si mesma pudesse ainda conservar. O exercício expansivo da epoché permite à teoria do conhecimento atravessar um "portal" (metáfora utilizada por Husserl nas lições de 1906/1907), através do qual se tona possível iniciar a "tarefa positiva" (positive Aufgabe), por meio da qual aspiramos à apreensão da essência do fenômeno cognoscitivo. A realização desta nova tarefa é o que permitirá à teoria do conhecimento ser alçada ao estatuto de "fenomenologia do conhecimento". Vejamos. ção por uma "eidética do conhecimento"

O exercício expansivo da epoché torna possível a abertura de um novo campo de investigação em cuja imanência o fenômeno do conhecimento se revelaria, objetivamente, como dado "efetivo e autêntico" (wirkliche und eigentliche Gegebenheit). Trata-se, portanto, nos termos de Husserl, em abrilmaio de 1907, da abertura de uma "terra firme de dados" ("Festlande von Gegebenheiten"). Nas lições de 1906/1907, no § 34 do Capítulo V, Husserl se refere a este campo, nos seguintes termos: "o mundo dos fenômenos como esferas de dados absolutamente indubitáveis" (Die Welt der Phänomene als Sphäre absolut zweifelloserGegebenheiten). A submissão de todo o transcendente ao referido "índice de nulidade" torna-se um passo obrigatório para a abertura deste novo campo, entendido como esfera do genuíno e efetivo "dar-se em si mesmo das coisas", em cuja imanência tudo aquilo que aparecesse pudesse, então, se dar originariamente e, portanto, com evidenciação máxima, livre das limitações que a rela-

\section{A tarefa positiva: a aspira- ção empírica com o mundo circun-}


dante insiste em nos impor. Se o exercício generalizado da suspensão de juízo se torna obrigatório para a abertura de uma nova objetividade, o método da redução fenomenológica desloca, definitivamente, a teoria do conhecimento para este novo campo. Para Husserl, faz-se necessário elevar intuitivamente à consciência da universalidade as objetalidades universais deste campo, tornando possível uma "investigação de essências" (Wesensforschung) e, com isso, uma doutrina da essência do conhecimento. A abertura do campo fenomenal revela-nos o que Husserl considera, no $\S 35$ do Capítulo 5 das lições de 1906/1907, o "verdadeiro ponto Arquimediano da filosofia" (der wahrhaft archimedische Punkt der Philosophie): "Mas, o verdadeiro ponto Arquimediano da filosofia encontra-se aí. É a questão de uma nuance, mas algo decisivo para a constituição de uma teoria do conhecimento possível e, por conseguinte, de uma filosofia verdadeira" (HUSSERL, [1906/1907] 1984, p. 211). Tal "ponto Arquimediano" coloca-nos, por sua vez, frente à distinção entre uma imanência psicológica (para a qual nos voltamos, enquanto homens efeti- vos e sobre a qual ainda incide o exercício da epoché) e uma "autêntica imanência", domínio do darse em si mesmo das coisas (para a qual a generalização da epoché nos deslocará a atenção).

É através do deslocamento de tais imanências que, enfim, a teoria do conhecimento poderá exercer a sua "tarefa positiva", por meio da qual conserva, no pensamento, a pergunta pela essência do conhecimento. Como o próprio Husserl nos diz, nas lições de 1906/1907, no Apêndice B, I: se trata agora de pensar a teoria do conhecimento como uma "teoria da essência do conhecimento" ("Wesenslehre der Erkenntnis"). Ou ainda, nos termos das lições de 1902/1903: "A teoria do conhecimento quer aclarar a essência do conhecimento..." (HUSSERL, [1902/1903] 2001, p. 75). O êxito em alcançar, por meio da redução fenomenológica, o que é reivindicado pela teoria do conhecimento é o que eleva essa teoria ao estatuto de "fenomenologia do conhecimento".

Porém, a tarefa crítica - necessária para que a teoria do conhecimento atingisse este estágio não deverá se ausentar. Husserl 
adverte-nos quanto ao risco iminente de tomarmos a tarefa positiva da teoria do conhecimento por uma explicação científico-natural do conhecimento como "fato natural", o que implicaria em tomar a teoria do conhecimento não em termos de fenomenologia do conhecimento, mas de "psicologia do conhecimento" e, portanto, em termos de uma ciência natural, cujas leis possuem, segundo Husserl, uma imprecisão (Vagheit), na medida em que as mesmas carecem de valor absoluto. Como diz Husserl, retomando uma lição que já estava anunciada desde Prolegômenos (1900), em suas lições de 1902/1903: "Como é concebível que, a partir de antecedentes vagos, devam emergir, das leis da psicologia, normas absolutamente exatas? O que é derivado de registros aproximados, também deve ter um caráter aproximado" (HUSSERL, [1902/1903] 2001, p. 20).

Daí o próprio Husserl alertar, poucos anos depois, no $\S 32$ do Ca- confundindo, com isso, teoria do pítulo 5 das lições de 1906/1907, conhecimento com psicologia. A para a tentação de tomarmos uma tentação naturalista de fundamencoisa em termos da outra: "Nós não tar a teoria do conhecimento em devemos sucumbir à tentação muito termos de uma "psicologia do cogrande de misturar teoria do conhe- nhecimento" implicaria em um cimento e psicologia" (HUSSERL, psicologismo que, por sua vez,

[1906/1907] 1984, p. 174). Tal tentação implicaria em um retorno ao modo de consideração natural que, apoiado na doutrina do naturalismo, incorreria em problemas de fundamentos (pois, confundiria a objetividade e idealidade com a subjetividade), não deixando, conforme vimos, de incorrer em um ceticismo iminente. Tomar a teoria do conhecimento em termos de psicologia do conhecimento implicaria em tomar a autêntica imanência do campo fenomenal em termos de uma imanência psicológica. Eis o que Husserl considera, ainda na linha das metáforas cristãs, no 332 do Capítulo 5 das lições de 1906/1907, o "pecado especificamente teórico-cognoscitivo, o pecado contra o Espírito Santo da filosofia" (HUSSERL, [1906/1907] 1984, p. 176). Trata-se, segundo Husserl, do "pecado original que humanos incorrem no estado de inocência teórico-cognoscitiva" (HUSSERL, [1906/1907] 1984, p. 176),

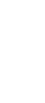


para usar os termos de Husserl, isso, encontramo-nos em condições em suas lições de 1902/ 1903, in- de exercer uma técnica de "varicorreria em um "pecado mortal" ação imaginária dos objetos": re(Todsünde) contra a teoria do co- tenho, ao exercer a redução fenonhecimento. É, portanto, uma me- menológica, o núcleo invariante da táfora sobre a qual Husserl insiste coisa, isto é, o que persiste na coisa em dar ênfase já alguns anos antes pensada mesmo diante de todas as das lições de 1906/1907, na esteira variações as quais a submeto arde uma preocupação denunciada bitrariamente em minha imaginapelo próprio autor desde 1900 e ção. Não se trata agora de visar transmitida por ele próprio desde esta ou aquela singularidade per1896, ainda no período de Halle.

Portanto, para evitar o risco deste tal deslocamento, impõe-se à teoria do conhecimento a exigência de adotar um método por intermédio do qual a elucidação da essência do conhecimento se tornaria possível. Conforme Husserl destaca, nas suas primeiras considerações sobre o tema, com a redução fenomenológica, passamos do fato individual para o que há nele de genérico. O exercício da redução fenomenológica assegura-nos a possibilidade de falarmos de uma eidética (ou de uma "doutrina de essências"). A redução fenomenológica exige-nos, como vimos, que tudo o que é transcendente possa ser submetido a um índice de nulidade, forçando-nos à abstenção de considerações sobre toda e qualquer posição de existência. Com filada na imaginação, mas sim, o que é visado "em geral". Nos termos de Husserl, o "universal idêntico" (identische Allgemeine) destacado visualmente a partir desta e daquela intuição singular. A variação arbitrária de um objeto qualquer na imaginação permite-nos notar que tal arbitrariedade não pode ser completa, uma vez que há condições necessárias sem as quais as próprias variações deixam de ser variações daquilo que se intenciona no pensamento. Cada uma dessas possibilidades que se perfilam na imaginação compartilha, necessariamente, com as demais, algo de invariante, coincidindo em relação ao caráter necessário do que é intencionado. A apreensão deste núcleo invariante é o que Husserl denominou de "visão de essências" (Wesenschau). 
Pode-se dizer, portanto, que a a sua tarefa positiva, a teoria do redução fenomenológica consiste, conhecimento é, enfim, alçada ao inicialmente, em uma "redução ei- estatuto de fenomenologia do codética", por intermédio da qual a nhecimento. Nos termos de Husteoria do conhecimento cumpriria serl: "Para este fim, a teoria do coa sua tarefa positiva, deslocando- nhecimento é antes de tudo uma nos a atenção para a essência do fenomenologia do conhecimento" fenômeno do conhecimento que, (HUSSERL, [1902/1903] 2001, p. para Husserl, consiste, propria- 76), de modo que o que vale para a mente, na intentio. Afinal, con- teoria do conhecimento-enquanto forme esclarece Husserl, todas as fenomenologia do conhecimento vivências congnoscitivas - a des- possa valer como um "fragmento peito das variações as quais pode- primeiro e básico" (e, portanto, mos submetê-las na imaginação - como uma "porta de entrada") para são vivências "de algo", dirigem- a fenomenologia em geral.

se, necessariamente, para alguma coisa, supostamente cognoscível. Tais vivências cognoscitivas possuem, sem admitir a possibilidade do contrário e, portanto, como algo que lhes pertence essencialmente, um "visar" (meinen), sempre dirigido a uma objetalidade. Se no que se refere ao conhecimento transcendente, o visar aparece encerrado em um enigma, na medida em que se revela, pela redução fenomenológica, enquanto um "dado efetivo e absoluto" (wirkliche und absolute Gegebenheit), como essência do fenômeno cognoscitivo, a intentio reaparece, na imanência do campo fenomenal, livre do assédio deste enigma. Ao exercer

\section{Considerações finais}

Por fim, no período de Göttingen, Husserl nos faz ainda uma importante revelação: do exercício da crítica do conhecimento, exercício por meio do qual são denunciadas as formas de ceticismo (e, por conseguinte, os contrassensos teoréticos que lhes são inerentes) em relação à possibilidade do conhecimento, resulta, por parte da teoria do conhecimento, uma "vocação" para fundamentar a metafísica. Daí Husserl dizer, nas "Cinco Lições" de abril-maio de 1907, que: "A crítica do conhecimento é, neste sentido, a condição da possibilidade da metafí- 
sica" (HUSSERL, [1907] 1950, p. uma "interpretação última” ("letzte 3). Ou seja, dessa crítica, de- Interpretation") de tudo o que se pende, segundo Husserl, a possi- doa originariamente à consciência bilidade de uma metafísica, defi- - por meio da referida crítica. nida, nos termos do autor, como: "a ciência do ser em sentido absoluto e último" (HUSSERL, [1907] 1950, p. 32). Também nas lições do mesmo período, de 1906/1907, no $\S 32$ do Capítulo 5, o autor nos diz: "Aqui, nós teríamos simplesmente a dizer que a metafisica pressupõe a teoria do conhecimento...Por conseguinte, ela não pode ser a base da teoria do conhecimento" (HUSSERL, [1906/1907] 1984, p. 177). Ou ainda, nas lições de 1909, quando Husserl afirma que: "Teoria do conhecimento como ciência relaciona-se ao conhecimento em geral. Ela não é propriamente metafísica, mas fundamento de toda metafísica" (HUSSERL, [1909] 2005, p. 37). Alguns anos antes, nas lições de 1906/1907, Husserl sugere-nos, no $\S 33$ do Capítulo 5, uma ampliação do termo "metafísica", de modo que pudéssemos falar não meramente de uma metafísica da natureza e da vida do espírito, anterior à crítica do conhecimento, mas da possibilidade de uma tomada de posição metafísica - no sentido de

Sendo assim, como "ciência do ser em sentido absoluto e último", a metafísica somente se torna possível com a abertura do solo fenomenal, sem a qual nada se poderia elucidar, clarificar e justificar em sentido último. Por conseguinte, no Apêndice B, I, Husserl nos diz que: “...eu não posso querer dirigir nenhuma metafísica antes da teoria do conhecimento...toda metafísica implica de certo modo em uma teoria do conhecimento..." (HUSSERL, [1906/1907] 1984, p. 402). Portanto, para Husserl, eu não posso tomar nenhuma ciência, conhecimento, juízos como pressuposições válidas (anteriormente à crítica da razão teórica), mas somente posso tomá-los como "fenômenos". É preciso, portanto, convertê-los em fenômenos, isto é, fazê-los aparecer, mediante a generalização da epoché e redução fenomenológica, como dados efetivos e absolutos na imanência do campo fenomenal, domínio de conhecimento absoluto e, como nos diz Husserl, em sua lição de 1909: “...isso é mesmo conhecimento me- 
tafísico em nosso sentido prefe- a qual o que é intencionado revelarido" (HUSSERL, [1909] 2005, p. se em sua totalidade como "fenô37).

meno". Aspirando, por variação

Daí a metafísica não poder pre- imaginária, a uma visão da essênceder à teoria do conhecimento cia do conhecimento, a teoria do que, como ciência do conheci- conhecimento lançar-se-ia - sem mento em geral, não é propria- perder de vista a sua tarefa crítica mente metafísica, mas, antes sim, (do contrário, se confundiria com o que a torna possível. Neste uma psicologia do conhecimento) sentido, a teoria do conhecimento - em um domínio de conhecimen- enquanto "Filosofia Primeira", tos absolutos, investindo-se de um para usar os termos de Husserl - espírito metafísico que ela mesma consiste em uma ciência privilegi- tornou possível. Eis a circulariada nas lições de Göttingen. Ao dade que é própria de sua "vocaexercer a crítica da razão teorética, ção". O leitor das lições mencioa teoria do conhecimento não se nadas no presente artigo poderia confunde com a metafísica. Ao ainda se perguntar: quais as implitraçar um itinerário crítico, gene- cações de tal circularidade? No enralizando a epoché como estratégia tanto, uma análise mais detalhada metodológica, a teoria do conhe- de tais implicações no decorrer do cimento nos conduz à abertura de itinerário husserliano ficará para um campo em cuja imanência dá- outra ocasião.

se uma autêntica objetividade para

\section{Referências bibliográficas}

HOUSSET, E. Husserl et l'énigme du monde. Paris: Éditions du Seuil, 2000.

HUSSERL, E. Logische Untersuchungen. Erster Band. Prolegomena zur reinen Logik. Halle a. d. S.: Max Niemeyer, ([1900] 1913).

. Allgemeine Erkenntnistheorie - Vorlesung 1902/03. Husser-

liana: Materialien (Band III). Dordrecht, Netherlands: Springer-

Science + Business Media, BV ([1902/1903] 2001). 
. Einleitung in die Logik und Erkenntnistheorie - Vorlesungen 1906/07. Husserliana (Band XXIV). Dordrecht, The Netherlands: Martinus Nijhoff, ([1906/1907] 1984).

. Die Idee der Phänomenologie - Fünf Vorlesungen. Husserliana (Band II). Netherlands: Martinus Nijhoff, ([1907] 1950). . Einführung in die Phänomenologie der Erkenntnis. Vorlesung 1909. Husserliana: Materialien (Band VII). Dordrecht, Netherlands: Kluwer Academic Publishers,([1909] 2005).

MOHANTY, J. N. "The development of Husserl's thought". In: Smith, B. \& Woodruff Smith, D (orgs) The Cambridge Companion to Husserl. Cambridge: Cambridge University Press, 1995, pp. 45-77.

TOURINHO, C. D. C. “O desafio metodológico de Husserl, o exercício generalizado da epoché e o estatuto transcendental da objetividade fenomenológica". In: Revista Portuguesa de Filosofia - Fenomenologia e Filosofia Prática, V 71, No 1, 2015, pp. 11-25. 
